\title{
The 7th International Conference on Webometrics, Informetrics and Scientometrics \& 12th COLLNET Meeting
}

\author{
Hildrun Kretschmer • Bülent Özel • Wolfgang Glänzel
}

Received: 30 January 2012/Published online: 29 February 2012

(C) Akadémiai Kiadó, Budapest, Hungary 2012

The 7th International Conference on Webometrics, Informetrics and Scientometrics \& 12th COLLNET Meeting took place in Istanbul, Turkey on 20-23 September 2011. This joint meeting was organised under the auspices of the international organisation COLLNET and by the Computer Science Department of the Istanbul Bilgi University with the participation of TÜBITAK ULAKBIM (The Turkish Academic Network and Information Centre) and Istanbul Bilgi University Library and Information Center. The event was hosted by the Istanbul Bilgi University.

The previous COLLNET meetings, part of which were jointly organised with other events, such as since 8 years with the international conferences on Webometrics, Informetrics and Scientometrics (WIS), had been held in Berlin (Germany) in 2000, New Delhi (India) in 2001, Sydney (Australia) in 2001, Beijing (China) in 2003, Roorkee (India) in 2004, Stockholm (Sweden) in 2005, Nancy (France) in 2006, New Delhi (India) in 2007, Berlin (Germany) in 2008, Dalian (China) in 2009 and Mysore (India) in 2010.

The conference attracted about 120 participants from 25 countries. At the conference, about 75 oral presentations and 20 poster presentations were delivered. For the present special issue of Scientometrics we have selected 3 keynotes by Pudovkin, Kretschmer, Stegmann et al. on research evaluation (Part I and II), by Beaver on "quantity and quality",

H. Kretschmer

Faculty of Business Administration/Business Computing, University of Applied Sciences Wildau, Wildau, Germany

H. Kretschmer

COLLNET-Center, Hohen Neuendorf, Germany

B. Özel

Computer Science Department, Istanbul Bilgi University, Istanbul, Turkey

W. Glänzel $(\bowtie)$

Centre for R\&D Monitoring (ECOOM) and Department of MSI, KU Leuven, Leuven, Belgium e-mail: Wolfgang.Glanzel@econ.kuleuven.ac.be

W. Glänzel

Department of Science Policy \& Scientometrics, Library of the Hungarian Academy of Sciences, Budapest, Hungary 
and by Glänzel on network and cluster representation, as well as 11 contributed papers. Another selection of keynotes and contributed papers will be part of a dedicated issue of the COLLNET Journal of Scientometrics and Information Management (CJSIM). ${ }^{1}$

The following event of this conference series, the 8th International Conference on Webometrics, Informetrics and Scientometrics (WIS) \& 13th COLLNET Meeting will be held at the Korea Institute of Science and Technology Information in Seoul (Korea), on 23-26 October 2012.

${ }_{1}$ CJSIM, Vol. 6, No. 1, June 2012 (http://www.tarupublications.com/journals/cjsim/cjsim.htm). 